\title{
Collaborative Rebate Strategy of Business-to-Customer Platforms Considering Recycling and Trade-Ins Simultaneously
}

\author{
Guojun Ji ${ }^{1}$, Zhongfeng Sun ${ }^{1, *(D)}$ and Kim Hua Tan ${ }^{2}$ D \\ 1 School of Management, Xiamen University, Xiamen 361005, China; jiking@xmu.edu.cn \\ 2 Nottingham University Business School, The University of Nottingham Jubilee Campus, \\ Nottingham NG8 1BB, UK; kim.tan@nottingham.ac.uk \\ * Correspondence: laowu-50@163.com
}

Citation: Ji, G.; Sun, Z.; Tan, K.H Collaborative Rebate Strategy of Business-to-Customer Platforms Considering Recycling and Trade-Ins Simultaneously. Sustainability 2021,

13, 1679. https://doi.org/

10.3390/su13041679

Academic Editor: Hyunchul Ahn

Received: 8 December 2020

Accepted: 1 February 2021

Published: 4 February 2021

Publisher's Note: MDPI stays neutral with regard to jurisdictional claims in published maps and institutional affiliations.

Copyright: (c) 2021 by the authors. Licensee MDPI, Basel, Switzerland. This article is an open access article distributed under the terms and conditions of the Creative Commons Attribution (CC BY) license (https:// creativecommons.org/licenses/by/ $4.0 /)$.

\begin{abstract}
B2C (business to customer) platforms like JD.com and Suning.com often cooperate with professional recycling companies, and implement recycling programs and trade-in programs simultaneously, especially for electronic products. The former means that platforms recycle old products from customers with cash, whereas the latter means that platforms allow customers to trade in old products for new ones. Under this background, we discuss how to develop the optimal rebate strategy for $\mathrm{B} 2 \mathrm{C}$ platforms based on the market recovery price of old products, and give the optimal rebate prices and feasible conditions of single-rebate, dual-rebate, and none-rebate strategies. The results show that the single-recycling rebate strategy is dominant when the residual value of old products is low, and when the residual value of old products is high, platforms should choose in turn the single-trade-in rebate strategy, dual-rebate strategy, single-recycling rebate strategy, and non-rebate strategy with the increase in the cost of new products. In order to obtain higher profits, B2C platforms should provide appropriate rebates to better coordinate the recycling program and the trade-in program on the basis of the market recovery price, the residual value, and the durability of old products as well as the cost, the selling price, and the upgrade range of new products.
\end{abstract}

Keywords: trade-ins; recycling rebate; $\mathrm{B} 2 \mathrm{C}$ platforms; collaborative rebate

\section{Introduction}

In order to encourage customers who are still using old products to buy upgraded new products, B2C (business-to-customer) platforms often implement trade-in programs. At the same time, they offer recycling programs to customers under the pressure from environmental regulations, from which they could make profits. For example, JD.com sells new smartphones by leading Huawei, Apple, and Samsung through the trade-in program and also recycles relevant old smartphones. Through numerical experiments, Xiao and Zhou [1] found that the implementation of the trade-in program and the recycling program simultaneously is more favorable to an enterprise.

Two ways are available on B2C platforms to those customers holding old products to acquire the value of old products: One is to sell them for cash only via the recycling program, and the other to exchange them for upgraded new products via the trade-in program at a preferential price. Certainly, customers can choose to keep using their old products, but when they decide to sell them, old products can either be recycled or traded in for new ones, that is, they cannot enjoy both benefits. Smartphone recycling is an example. The recycling process is as follows: Customers have their old products evaluated online and then submit an order for recycling on the platform before a recycling collector comes to pick up the items. Only after old products are tested do they get the money. The difference between the trade-in process and the recycling process lies in that customers could purchase the new product at a discount price after deducting the recycling price according to the online evaluation result. 
Considering the complexity of recycling, most B2C platforms cooperate with professional recycling companies. Especially when testing and evaluation of old products are involved, the recycling business is usually outsourced by B2C platforms to recycling companies. For example, JD.com and Suning.com have developed strategic cooperation with Aihuishou and Tcbang recycling companies, respectively. Under this cooperative mode, the market recovery price of old products is determined by recycling companies according to such factors as the old product status and the second-hand market, which constitutes an exogenous variable to $\mathrm{B} 2 \mathrm{C}$ platforms.

Based on the market recovery price decided by recycling companies, $\mathrm{B} 2 \mathrm{C}$ platforms can decide on their own whether or not to offer customers additional rebates. For example, on 14 January, 2021, JD.com offered a rebate of CNY 40 through the recycling program for old Huawei P20 phones if the recovery price is over CNY 500, but if customers choose to purchase the new Huawei Mate 40 through the trade-in program, they can get a rebate of CNY 50 for the same old phones. When the recovery price of old Huawei P20 phones is between CNY 300 and 500, customers can still get a recycling rebate of CNY 25; however, they get no trade-in rebates even if they buy new Huawei Mate 40. If the recovery price is less than CNY 300, customers can get no additional rebates either for trade-ins or for recycling. In fact, platforms usually do not offer any rebates when the recycling value of old products is very low. Therefore, B2C platforms can choose to provide single-recycling rebates to encourage customers to sell their old products, to provide single-trade-in rebates to stimulate sales of new product, and to provide dual rebates to maximize the total revenue from the two programs. Of course, B2C platforms could choose not to offer additional rebates.

Based on the above realistic background, we propose the following three research problems:

(1) On the basis of the exogenous market recovery price of old products, how do B2C platforms choose the optimal collaborative rebate strategy when considering the implementation of the recycling program and the trade-in program simultaneously? Nonrebate, single rebate, or dual rebate?

(2) How do B2C platforms set the optimal rebate price? What are the feasible conditions for each rebate strategy?

(3) How do the relevant parameters of old products and new products affect the rebate strategies?

Although more and more customers tend to sell their old products or buy new products through trade-ins on B2C platforms, only a few studies taking B2C platforms as the research object have been conducted. And as of now, no literature has been found that considers both the recycling program and the trade-in program as well as the operation characteristics of both programs on $\mathrm{B} 2 \mathrm{C}$ platforms. The primary purpose of this paper is to fill this gap. We take comprehensive B2C platforms such as JD.com and Suning.com as our research object. Compared to ordinary enterprises, B2C platforms are different in two ways. On the one hand, other than manufacturers and ordinary retailers who serve as the only decision-making body on the recovery price of old products, B2C platforms give that decision right to their partners, i.e., professional recycling companies, and only decide whether or not to provide customers with additional rebates based on the recovery price of old products. On the other hand, customers may use the rebates released to their virtual accounts to buy other products on the platforms, which results in cross-selling benefits. Besides, the selling price of new updated products is often the market uniform price set by manufacturers. Based on those factors and consumer utility theory, we build a theoretical model and discuss the four different strategies that $\mathrm{B} 2 \mathrm{C}$ platforms might adopt and the feasible conditions of each strategy, that is, how B2C platforms choose the most favorable collaborative rebate strategy according to the residual value of old products and the profitability of new products. In the extended discussion, we examine the changes of platforms rebate strategies when the market recovery price is very high and zero, and analyze the influences of cross-selling on collaborative rebate strategies. We obtain some findings 
and managerial implications that can be referential for B2C platforms to coordinate the recycling and trade-in programs.

The rest of this paper is outlined as follows. We review the related literature in Section 2. In Section 3, we introduce the model setting and discuss the behavioral choices of customers in the face of the recycling program and the trade-in program, and get the profit functions of B2C platforms. We then study the optimal rebate strategies of B2C platforms and analyze the influences of the relevant parameters in Section 4, and give some extended discussions on the model in Section 5. Finally, we draw the conclusions in Section 6. All the proofs of our paper are shown in the Appendix A.

\section{Literature Review}

Our paper is closely related to the literature on the recycling of old products and tradeins. Abundant research has been conducted on recycling old products, which involves the channels of recycling [2-4], disposing of old products [5,6], governmental regulations [7-9], and so on. Under the government's recycling regulations, the recycling of old products through proper recycling channels and refurbishment or remanufacturing old products are not only profit-making to enterprises, but also have good social value and environmental benefits. Some scholars have conducted extensive research on trade-ins by considering various factors, such as closed-loop supply chain [10,11], remanufacturing [12,13], dual-channels [14], secondary market [15], rollover [16,17], customer behavior [18,19], etc. Different from the recycling program, the trade-in program dovetails the recycling end with the selling end, which can serve as a tool to reduce the negative impact of the lemon problem [20], in addition to implementing price discrimination conveniently and stimulating the sale of new products [21].

With the progress of information technology and the popularization of the Internet, more and more transactions of recycling and trade-ins are transferred to online channels. Wang et al. [22] studied the impact of green information on customers' willingness to recycle old products online through two experiments. Miao et al. [23] studied the online-tooffline recycling mode based on the classification process of old products, which integrates the upstream and downstream resource on network platforms and improves the efficiency of recycling. Cao et al. [24] took B2C platforms as their research object, considered self-run stores of platforms and third-party stores simultaneously, and comparatively investigated the advantages and disadvantages of the two different trade-in rebates, i.e., gift cards that can only be used in self-run stores and cash coupons that can be used in both stores. Cao et al. [25] considered the cases in which gift cards might expire or be discarded by customers, and gave the boundary conditions under which B2C platforms choose between cash payment and gift card payment as the trade-in rebate.

To sum up, the literature on the recycling of old products does not consider trade-ins, and the recycling of old products is not taken into consideration in the literature on tradeins, either. The practice of considering recycling and trade-ins simultaneously on such comprehensive platforms as JD.com and Suning.com is very common now. However, it is rare to find studies concerning the combination of recycling and trade-ins. To the best of our knowledge, the only relevant paper was published by Xiao and Zhou [1]. They considered the choice behavior of the customers who aim to maximize the value of their old products, that is, trade in for cash or trade in for an upgrade, and took into account the situations of whether newly arrived customers buy new products or refurbished products. Meanwhile, they discussed an enterprise's optimal pricing when both the recycling program and the trade-in program are offered to customers. The following three aspects differentiate our paper from the existing literature, and from Xiao and Zhou [1] in particular.

(1) The decision-making bodies: We focus on B2C platforms and consider the features of B2C platforms implementing recycling and trade-in programs, which include not only the pricing mechanism and the strategy profile, but also the cross-selling benefits when customers use rebates for consumption again on the platforms that are covered in the extended discussion. Cao et al. [24] and Cao et al. [25] considered the features of the sales 
models and the trade-in rebate forms on $\mathrm{B} 2 \mathrm{C}$ platforms without referring to the recycling issue. Xiao and Zhou [1] did not use B2C platforms as their research object.

(2) The pricing mechanism: Our paper takes the realistic cooperation between B2C platforms and recycling companies into account and goes into detail about the structure of old product prices and the pricing mechanism. For B2C platforms, the market recovery price of old products is an exogenous variable determined by recycling companies, who can only decide upon the range of rebates based on the market recovery price. As far as customers are concerned, the value of old products is made up of the market recovery price and the extra rebate offered by platforms. Such a pricing mechanism is more in line with the practical operation of $\mathrm{B} 2 \mathrm{C}$ platforms. In the existing literature either on recycling or on trade-ins, the recovery price of old products is determined by the only decision-making body, i.e., retailers, manufacturers, or recycling companies. Under the implementation of recycling and trade-ins simultaneously, Xiao and Zhou [1] still held that both rebates of old products in the recycling program and the trade-in program are decided by a single enterprise.

(3) The strategy profile: Xiao and Zhou [1] gave optimal pricing when enterprises offered both recycling and trade-in programs. In regards to whether enterprises should implement either the recycling program or the trade-in program or both programs simultaneously, they did not make any strict derivation or detailed analysis through a theoretical model. Instead, after setting the relevant parameters just according to the data from the company Apple, they came to the single conclusion through numerical experiments that the simultaneous implementation of both programs is always more favorable than implementing one program alone. In reality, however, B2C platforms are faced with more complicated strategy choices due to the differences in the pricing mechanism. Based on the exogenous recovery price of old products, we give through theoretical derivation the feasible conditions of the single-recycling rebate strategy, single trade-in rebate strategy, dual-rebate strategy, and non-rebate strategy of B2C platforms. By detailing the strategy choices when $\mathrm{B} 2 \mathrm{C}$ platforms adopt both recycling and trade-in programs, we can provide platforms with richer decision-making references.

\section{The Model}

A comprehensive B2C platform that sells products of various categories and brands and also recycles old products was taken as the object of our study. The recovery price is determined by a cooperative recycling company and considers the market recovery price. When submitting an order for recycling, customers report truthfully the status of their old products and obtain a real-time market recovery price. It is assumed that the evaluated price of old products given online is in accord with the price upon actual testing. The relevant notations are shown in Table 1.

Table 1. Notations.

\begin{tabular}{cc}
\hline Notation & Description \\
\hline$p_{j}^{i}$ & $\begin{array}{r}\text { Platform's optimal rebate price with } i \text { standing for different rebate } \\
\text { strategies, and } j=r, t \text { for the recycling program and trade-in } \\
\text { program, respectively }\end{array}$ \\
$s$ & $\begin{array}{c}\text { Market recovery price of old products } \\
p\end{array}$ \\
$c$ & Residual value of old products for the platform \\
$\theta$ & Durability of old products \\
$v$ & Unit cost of new products for the platform \\
$\pi_{i}$ & Upgrade range of new products \\
& Customers' willingness to pay for the quality of products \\
Platform's profit with $i$ standing for different rebate strategies
\end{tabular}

The platform is now selling an upgraded product, for example, an upgrade of the same series of phones or computers. The quality of new product is $1+\theta$, and $\theta>0$ 
stands for the upgraded range of the product, i.e., the improvement in its performance. The new product price $p$ is the unified retail price on the Internet determined by the manufacturer and the wholesale cost for the platform is $c$. Assuming that the durability of the previous generation of the product is $\delta<1$, and the recovery price is $p_{c}, p_{c}<\delta$ to ensure the economical concern about recycling old products for the relevant enterprises. The platform's rebates for recycling and trade-ins are represented by $p_{r} \geq 0$ and $p_{t} \geq 0$, respectively, which refer to the additional rebates offered by the platform, excluding the market recovery price of the old product.

Since our paper aims to discuss the rebate strategies in the case of recycling and trade-ins, we only studied all customers who held old products without considering newly arrived customers. It is obvious that newly arrived customers do not have any direct impacts on the platform's rebate strategies concerning old products. Ciao et al. [24] also just considered those customers holding old products. Without loss of generality, we normalized the potential market size as "1." Customers' willingness to pay (hereinafter referred to as WTP) for the quality of products $v$ is uniformly distributed over $[0,1]$. The utilities of the customers' choices of participating in recycling programs and trade-in programs and keeping old products are respectively as follows:

$$
\begin{gathered}
U_{r}=p_{c}+p_{r} \\
U_{t}=(1+\theta) v-p+p_{c}+p_{t} \\
U_{k}=\delta v
\end{gathered}
$$

when $U_{r} \geq U_{k}$, i.e., $v \leq \frac{p_{c}+p_{r}}{\delta} \triangleq v_{r}$, customers' choice of recycling is better than that of keeping old products; when $U_{t} \geq U_{k}$, i.e., $v \geq \frac{p-p_{c}-p_{t}}{1+\theta-\delta} \triangleq v_{t}$, it is better for customers to choose trade-ins than to retain their old products. If $v_{r} \leq v_{t}$, the customers with WTP on $\left[0, v_{r}\right]$ choose to have their old products recycled, whereas the customers with WTP on $\left[v_{r}, v_{t}\right]$ choose to keep their old products and the customers with WTP on $\left[v_{t}, 1\right]$ choose to trade in old products for new ones. If $v_{r}>v_{t}$, the utilities of recycling and of trade-ins for the customers whose WTP is within the range of $\left[v_{t}, v_{r}\right]$ are both greater than those of retaining old products. From $U_{t} \geq U_{r}$, we get $v \geq \frac{p-p_{t}+p_{r}}{1+\theta} \triangleq v_{t r}$. Therefore, the customers with WTP on $\left[0, v_{t r}\right]$ choose recycling and the others choose trade-ins. The customers' choice behavior in the above two situations is shown in Figure 1.

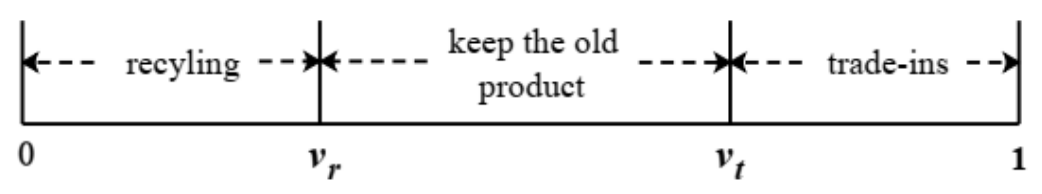

(a) When $v_{r} \leq v_{t}$

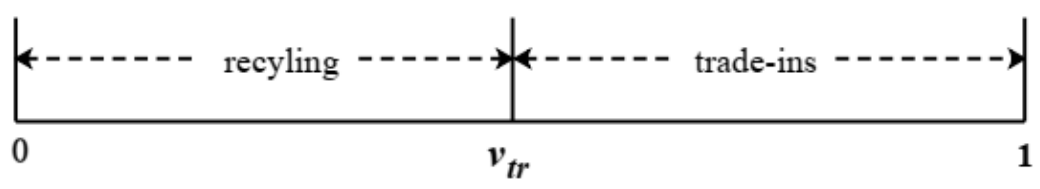

(b) When $v_{r} \geq v_{t}$

Figure 1. Choice behavior of customers.

The B2C platform's decision variables are $p_{r}$ and $p_{t}$, i.e., the platform chooses appropriate rebates for both recycling and trade-ins to maximize its revenue. If the platform does not offer any extra rebate, it means that the platform recycles old products at the market recovery price and does not implement the trade-in program. Now customers who want to purchase the upgraded products have to get their rebates through the recycling program first, that is, the trade-in process is done upon completion of the recycling process. Obviously, $p_{r}$ and $p_{t}$ are both $0, v_{r}=\frac{p_{c}}{\delta}$, and $v_{t}=\frac{p-p_{c}}{1+\theta-\delta}$. In addition, $\frac{p_{c}}{\delta}<\frac{p-p_{c}}{1+\theta-\delta}$, i.e., 
$p_{c}<\frac{\delta p}{1+\theta}$, which means there are some customers who choose to keep their old products at the market recovery price, which is consistent with most situations. The platform's decision analysis meets the above condition in the subsequent part, and we further analyze the situation when $p_{c} \geq \frac{\delta p}{1+\theta}$ in the extended discussion.

Under the platform's rebate strategy, when $v_{r} \leq v_{t}$, that is, some customers might still be willing to use their old products, the platform's profit function is:

$$
\begin{gathered}
\pi=\left(p-c+s-p_{c}-p_{t}\right)\left(1-v_{t}\right)+\left(s-p_{c}-p_{r}\right) v_{r} \\
\text { s.t. } p_{r} \geq 0 \\
p_{t} \geq p_{r} \\
v_{r} \leq v_{t}
\end{gathered}
$$

On the right side of Profit Function (1), the first item refers to the profits from the tradein program and the second item is the profits from the recycling program. Constraint (2) means that the recycling rebate is nonnegative, and the equal sign means no rebate is offered for recycling. Constraint (3) means the rebate for trade-ins is not less than that for recycling. This is because customers can bypass the trade-in program by getting the rebate money by recycling old products first and then buying news ones if the trade-in rebate is less than the recycling rebate, which makes the implementation of the trade-in program meaningless. In consequence, it is deemed that the trade-in program is not implemented when the two rebates are equal to each other. Constraint (4) means that some customers might refuse both recycling and trade-ins, as shown in (a) of Figure 1. The equal sign indicates that the platform exactly recycles all the old products under the implementation of both programs.

When $v_{r}>v_{t}$, all the old products are recycled in two ways, as shown in (b) of Figure 1. In order to get the profit function, Lemma 1 is given below.

Lemma 1. When $v_{r}>v_{t}, p_{r}=0$.

Lemma 1 shows that when the platform wants to encourage those customers who are only willing to have their old products recycled originally to buy new products through the trade-in program, offering zero recycling rebate minimizes the cost of trade-ins. At this point, the customers with WTP in $\left[v_{t}, v_{r}\right]$ choose a more favorable way between recycling and trade-ins so as to maximize their utilities, and the recycling demand is partly cannibalized by the trade-in demand. As $p_{r}=0, v_{r}=\frac{p_{c}}{\delta}, v_{t}=\frac{p-p_{c}-p_{t}}{1+\theta-\delta}$, and $v_{t r}=\frac{p-p_{t}}{1+\theta}$. The platform's profit function is as follows:

$$
\begin{gathered}
\pi=\left(p-c+s-p_{c}-p_{t}\right)\left(1-v_{t r}\right)+\left(s-p_{c}\right) v_{t r} \\
\text { s.t. } p_{t}>0 \\
v_{r} \geq v_{t}
\end{gathered}
$$

Constraints (6) and (7) indicate that only when the rebate for trade-ins is strictly greater than zero do some customers who originally choose recycling switch to tradeins. Different from the condition $v_{r}>v_{t}$ in Lemma 1, we considered the case $v_{r}=v_{t}$ here, which means all the old products are exactly recycled due to the trade-in rebate. By combining the situations in which Constraints (4) and (7) take equal signs, we could derive complete feasible conditions for the corresponding rebate strategies.

\section{Collaborative Rebate Strategy and Parameter Analysis}

Depending on whether to provide a combination of the recycling rebate and the trade-in rebate, the rebate strategies available to $\mathrm{B} 2 \mathrm{C}$ platforms include the single-recycling rebate strategy (only providing the recycling rebate through the recycling program and no 
implementation of the trade-in program), single-trade-in rebate strategy (only giving the trade-in rebate and recycling old products at the market recovery price), dual-rebate strategy (providing both the recycling rebate and the trade-in rebate), and non-rebate strategy (providing no extra rebate and just recycling old products at the market recovery price), represented by $R, T, T R$, and $B$, respectively.

There are three levels of recycling. The first is partial recycling. That is, some customers choose to keep their old products in addition to those who choose either recycling or tradeins. The second is exactly complete recycling — that is, the customers who choose recycling and the other customers who choose trade-ins just cover the whole group. The third is cannibalization complete recycling. That is, all the old products are recycled at this level, and the trade-in program cannibalizes the need of some customers who choose recycling at the market recovery price, which enables them to sell their old products and buy upgraded new products at the same time.

\subsection{Strategy R: Single-Recycling Rebate}

When the B2C platform provides the recycling rebate without considering trade-ins, $p_{t}$ is meaningless, and $p_{r}>0$. At this point, customers who want to purchase new products have their old products recycled first through the recycling program, that is, the rebate for purchasing new products is equal to the rebate for recycling. Therefore, it is treated as $p_{t}=p_{r}$ in order to solve the model.

Proposition 1. The feasible conditions and optimal rebates for the single-recycling rebate strategy are shown in Strategy $R_{1}$ and Strategy $R_{2}$ of Table 2, where $s_{1}=2 p_{c}, s_{2}=\frac{2}{1+\theta} \delta p$, $c_{1}=2 p-(1+\theta-\delta), c_{2}=\frac{1+\theta}{\delta} s-(1+\theta-\delta)$, and $c_{3}=\frac{1+\theta}{\delta} s-(1+\theta-\delta)+2 p-\frac{2(1+\theta)}{\delta} p_{c}$.

Table 2. Optimal solutions under different strategies.

\begin{tabular}{|c|c|c|c|c|c|}
\hline \multirow{2}{*}{ Strategy } & \multicolumn{2}{|c|}{ Feasible Condition } & \multirow{2}{*}{$p_{r}$} & \multirow{2}{*}{$p_{t}$} & \multirow{2}{*}{$\begin{array}{c}\text { Recycling } \\
\text { Range }^{1}\end{array}$} \\
\hline & $s$ & $c$ & & & \\
\hline$R_{1}$ & $\begin{array}{c}s_{1} \leq s \leq s_{2} \\
s>s_{2}\end{array}$ & $\begin{array}{l}c_{1}<c \leq c_{3} \\
c_{2} \leq c \leq c_{3}\end{array}$ & $\frac{s}{2}+\frac{\delta(2 p-c-1-\theta+\delta)}{2(1+\theta)}-p_{c}$ & - & PR \\
\hline$R_{2}$ & $s>s_{2}$ & $c_{1}<c<c_{2}$ & $\delta p /(1+\theta)-p_{c}$ & - & ECR \\
\hline$T_{1}$ & $s<s_{1}$ & $c_{4} \leq c \leq c_{5}$ & 0 & $\frac{2\left(p-p_{c}\right)+s-c-(1+\theta-\delta)}{2}$ & PR \\
\hline$T_{2}$ & $\begin{array}{l}s<s_{1} \\
s \geq s_{1}\end{array}$ & $\begin{array}{l}c_{6}<c<c_{4} \\
c_{6}<c<c_{7}\end{array}$ & 0 & $\frac{\delta p-(1+\theta) p_{c}}{\delta}$ & ECR \\
\hline$T_{3}$ & - & $c \leq c_{6}$ & 0 & $\frac{2 p-c-(1+\theta)}{2}$ & CCR \\
\hline$T R_{1}$ & $s_{1} \leq s \leq s_{2}$ & $c_{2} \leq c \leq c_{1}$ & $\frac{s}{2}-p_{c}$ & $\frac{2\left(p-p_{c}\right)+s-c-(1+\theta-\delta)}{2}$ & PR \\
\hline$T R_{2}$ & $\begin{array}{c}s_{1} \leq s \leq s_{2} \\
s>s_{2}\end{array}$ & $\begin{array}{l}c_{7} \leq c<c_{2} \\
c_{7} \leq c \leq c_{1}\end{array}$ & $\frac{1+\theta-\delta+c}{2(1+\theta)} \delta-p_{c}$ & $p-p_{c}-\frac{(1+\theta-\delta)(1+\theta-\delta+c)}{2(1+\theta)}$ & ECR \\
\hline$B$ & $\begin{array}{l}s<s_{1} \\
s>s_{1}\end{array}$ & $\begin{array}{l}\mathrm{c}>\mathrm{c}_{5} \\
\mathrm{c}>\mathrm{c}_{3}\end{array}$ & 0 & 0 & PR \\
\hline
\end{tabular}

${ }^{1}$ PR, ECR, and CCR mean partial recycling, exactly complete recycling, and cannibalization complete recycling, respectively, in Table 2.

Proposition 1 shows that in the case of no trade-ins, the platform is willing to provide the recycling rebate only when the residual value of old products is higher enough and the cost of new products is within an appropriate range. It is obviously uneconomical to provide the recycling rebate when the residual value of old products is too low. With the increase in the residual value, the platform's profitability through recycling old products rises, which becomes an impetus for increasing the quantity of recycled products by providing additional rebates until all the old products are recycled. The recycling rebate not only helps to increase the quantity of recycled products but also contributes to the increased number of customers who buy upgraded products after having their old ones recycled. If the cost of new products is relatively high, relatively low profits will not 
compensate for the expenditure on rebates for recycling; if the cost of new products is relatively low, the increased sales volume will be very limited by providing rebates for recycling old products. Therefore, the feasible condition for Strategy $R$ requires the cost of new products to be within an appropriate range.

\subsection{Strategy T: Single-Trade-in Rebate}

When the B2C platform implements the single-trade-in rebate strategy, $p_{r}=0, p_{t}>0$. Those customers who choose not to buy new products but rather sell old ones only receive compensation at the market recovery price.

Proposition 2. The feasible conditions and optimal rebates for the single-trade-in rebate strategy are shown in Strategy $T_{1}$, Strategy $T_{2}$, and Strategy $T_{3}$ of Table 2, where $c_{4}=s-(1+\theta-\delta)+\frac{2(1+\theta-\delta)}{\delta} p_{c}, c_{5}=s+2\left(p-p_{c}\right)-(1+\theta-\delta), c_{6}=\frac{2(1+\theta)}{\delta} p_{c}-$ $(1+\theta)$, and $c_{7}=\frac{2(1+\theta)}{\delta} p_{c}-(1+\theta-\delta)$.

Proposition 2 indicates that if the cost of new products is low enough and the unit profit from new products is high enough, the platform is always willing to provide customers with generous trade-in rebates no matter what the residual value of old products is when recycling old products just at the market recovery price. That is helpful for the platform to get more customers involved in the trade-in program, which results in complete recycling of all the old products. In addition, it stimulates some customers who intend only to have their old products recycled change their minds to buy new products through the trade-in program. With the increase in the cost of new products, the platform gets less motivated to provide trade-in rebates and chooses to give up cannibalizing the recycling demand, and the intensity of the rebates provided makes all the old products recycled exactly. When the cost of new products continues to grow, the profitability through tradeins keeps falling, and partial recycling of old products becomes a preferable choice to the platform. The residual value of old products also has impacts on the quantity of recycled old products through the single-trade-in rebate strategy. When the residual value is relatively low and the cost of new products is relatively high, the platform partly recycles old products; when the residual value is pretty high or the cost of new products is pretty low, the platform chooses to completely recycle old products.

\subsection{Strategy TR: Dual Rebate}

When the B2C platform provides the recycling rebate and the trade-in rebate simultaneously, $p_{t}>0, p_{r}>0$. No matter which channel customers choose, they receive additional rebates that are higher than the market recovery price.

Proposition 3. The feasible conditions and optimal rebates for the dual-rebate strategy are shown in Strategy $T R_{1}$ and Strategy $T R_{2}$ of Table 2.

Proposition 3 shows that the platform could not only stimulate the recycling demand through the recycling rebate, but also promote the sale of new products and increase the quantity of recycled old products through the trade-in rebate. Under the dual-rebate strategy, the residual value of old products cannot be too small, otherwise recycling old products becomes uneconomical, and the cost of new products must be within a reasonable range to ensure relatively high profitability from trade-ins. In addition, the trade-in program cannot be far more dominant than the recycling program, as the platform then becomes less motivated to implement the latter. The increasing residual value of old products and the decreasing cost of new products both facilitate the quantity of recycled old products, which helps with the transition from partial recycling to exactly complete recycling. 


\subsection{Strategy B: Non-Rebate}

When the platform does not provide additional rebates, obviously $p_{t}=0$ and $p_{r}=0$. Customers choose recycling and trade-ins by themselves both at the market recovery price.

Proposition 4. The feasible conditions for the non-rebate strategy are shown in Strategy B of Table 2.

Proposition 4 shows that when the cost of new products is high enough and few profits are made from the sales of new products, the platform should refuse to provide any additional rebates because both recycling and trade-in rebates stimulate customers to buy new products. At this moment, the platform recycles old products in part at the market recovery price.

The results of Propositions 1 to 4 are shown in Table 2. The expressions of the platform's profit functions are obtained by substituting the optimal rebates into Equations (1) and (5), as given in the proofs of the Appendix A.

\subsection{The B2C Platform's Optimal Rebate Strategy}

The optimal rebate strategy of the B2C platform can be obtained based on the conclusions of Propositions 1 to 4 .

Proposition 5. When the platform considers recycling and trade-ins simultaneously, the optimal decision-making path is shown in Figure 2 according to the residual value of old products and the cost of new products.

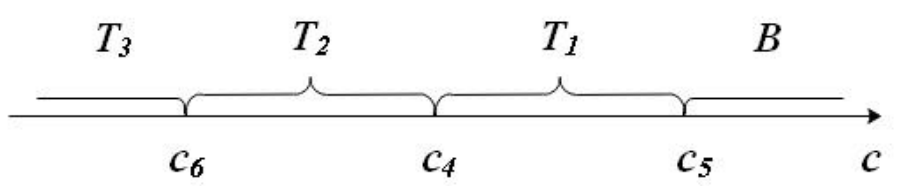

(a) When $s<s_{1}$.

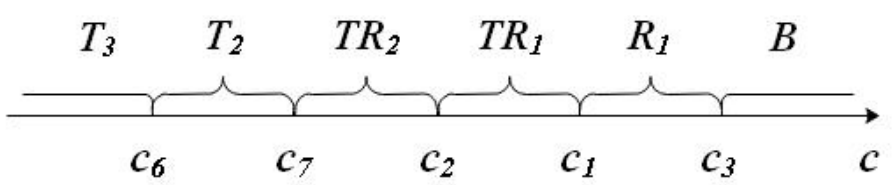

(b) When $s_{1} \leq s \leq s_{2}$.

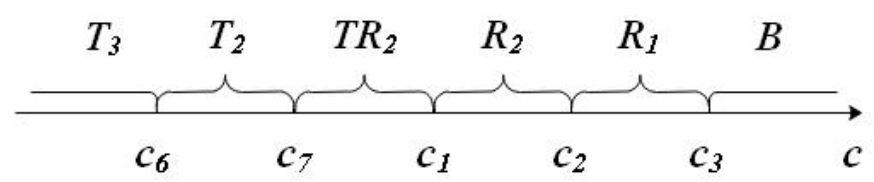

(c) When $s>s_{2}$.

Figure 2. The Platform's Optimal Rebate Strategy.

Proposition 5 shows that (1) when the residual value of old products is relatively low, the platform should choose the single-trade-in strategy. It is worth considering whether to provide the recycling rebate or not only when the residual value of old products exceeds a certain range, i.e., $s \geq s_{1}$. JD.com is an example. The platform requires the minimum recovery price when offering recycling rebates. For instance, JD.com gives a rebate of CNY 40 for recycling MI 8 phones whose recovery price must be over CNY 500. The tradein program is more applicable than the recycling program when the residual value of old products is relatively low because the former is profitable through both selling new products and recycling old products. JD.com gives a rebate of CNY 50 if the market recovery price of old phones is more than CNY 200 when customers purchase a new Honor 30 through the trade-in program. (2) With the decrease in the cost of new products, 
the platform tends to provide the rebate for trade-ins. When the cost of new products is very low, the platform makes fat profits through the single-trade-in rebate strategy, which encourages more customers to buy new products. Those customers who choose the recycling program originally at the market recovery price are even attracted to buying new products under high trade-in rebates. With the increase in the cost of new products, implementing recycling and trade-ins simultaneously becomes a more favorable choice for the platform because on the one hand, the decrease in the unit profit of new products makes it less necessary to provide an excessive rebate for trade-ins, but one the other hand, a higher residual value of old products means higher profits to make from recycling old products. When the cost of new products keeps rising, it is better to give up providing the trade-in rebate and implement the single-recycling rebate strategy if the residual value of old products is relatively high. However, if the cost of new products is very high and the profits generated from the sales of new products that are promoted by recycling rebates cannot cover the expenditure on the rebates, choosing not to provide any rebates at this time becomes a better decision. In other words, the cost of new products and the residual value of old products represent the economy of the recycling program and the trade-in program. The platform should consider the profitability through both programs and adopt the most favorable collaborative rebate strategy.

\subsection{Parameter Analysis}

Now we analyze the influences of some important parameters on the results, including the market recovery price $p_{c}$, the upgrade range of new products $\theta$, and the durability of old products $\delta$, etc.

Proposition 6. (1) $\frac{\partial p_{r}^{j}}{\partial p_{c}}<0, \frac{\partial p_{t}^{j}}{\partial p_{c}}<0$, and $\frac{\partial p_{t}^{T_{3}}}{\partial p_{c}}=0$, where $j=\left\{R_{1}, R_{2}, T_{1}, T_{2}, T R_{1}, T R_{2}\right\}$. (2) $\frac{\partial \pi_{i}}{\partial p_{c}}<0$ and $\frac{\partial \pi_{j}}{\partial p_{c}}=0$, where $i=\left\{T_{1}, T_{2}, T_{3}, B\right\}, j=\left\{R_{1}, R_{2}, T R_{1}, T R_{2}\right\}$. (3) $\frac{\partial c_{1}}{\partial p_{c}}=\frac{\partial c_{2}}{\partial p_{c}}=\frac{\partial s_{2}}{\partial p_{c}}=0, \frac{\partial s_{1}}{\partial p_{c}}>0, \frac{\partial c_{3}}{\partial p_{c}}<0, \frac{\partial c_{4}}{\partial p_{c}}>0, \frac{\partial c_{5}}{\partial p_{c}}<0, \frac{\partial c_{6}}{\partial p_{c}}>0$, and $\frac{\partial c_{7}}{\partial p_{c}}>0$.

Proposition 6 shows that the optimal rebates under all the strategies except Strategy $T_{3}$ decrease whereas $p_{c}$ increases and that the trade-in rebate under Strategy $T_{3}$ is independent of $p_{c}$. That is because it is cannibalization complete recycling under Strategy $T_{3}$, where the optimal trade-in rebate must make the WTP of the critical customer who could get equal utility from either recycling or trade-ins less than the WTP of another critical customer $\left(v=\frac{p_{c}}{\delta}\right)$ who chooses recycling at the market recovery price. Under the other strategies, the platform achieves either partial recycling or exactly complete recycling, and customers' choices are determined by the sum of the market recovery price and one of the two rebates. The critical customer $\left(v=\frac{p_{c}}{\delta}\right)$ will not choose the trade-in program and the total amount of money he can get in return for recycling and trade-ins is relatively stable. As a result, the platform decreases both the recycling rebate and the trade-in rebate when the market recovery price increases.

The platform's profits have nothing to do with $p_{c}$ under the single-recycling rebate strategy and the dual-rebate strategy. The reason lies in that the recycling rebates are positive and the total amount of money the platform pays customers for recycling or tradeins is higher than the market recovery price, which means the platform could fight off the effects of a change in the market recovery price on profits by increasing or decreasing the rebates. But the increase in $p_{c}$ weakens the platform's profitability under the non-rebate strategy and the single-trade-in strategy. In terms of Strategy $T_{1}$, the increase in $p_{c}$ has no effects on the profits from trade-ins, but a low residual value of old products cannot make up for the increase in the expenditure on recycling. Under Strategy $T_{2}$, the profitability of the trade-in program is higher than that of the recycling program due to the relatively low cost of new products. The critical customer with WTP in $\frac{p_{c}}{\delta}$ moves to the right with the increase of $p_{c}$, which leads to an increase in the relatively less profitable recycling demand. Under Strategy $T_{3}$, the increase in $p_{c}$ means an increase in the expenditure on trade-in 
rebates in the same quantity as recycled products even though the trade-in rebate remains stable. Under Strategy $B$, the cost of new products is relatively high under its feasible conditions and the platform's profitability through trade-ins is relatively low. As a result, the increase in the need for both recycling and trade-ins generated by the increase in $p_{c}$ is difficult to cover the platform's increased expenditure on the higher recovery price despite a relatively high residual value of old products.

A change in $p_{c}$ has obvious influences on the feasible region of each strategy. When $p_{c}$ increases, the feasible region where the platform should provide rebates shrinks considering both the residual value of old products ( $s_{1}$ increases) and the cost of new products $\left(c_{3}\right.$ and $c_{5}$ decrease) and the feasible region of Strategy $B$ expands. Therefore, the increase in $p_{c}$ narrows down the platform's operating room for rebate strategies. Comparatively speaking, the increase in $p_{c}$ has more influences on the recycling program than on the tradein program, such as the shrinkage of the feasible region $\left[c_{1}, c_{3}\right]$ of Strategy $R$ (including $R_{1}, R_{2}$ ) and an expansion of the feasible region of Strategy $T$ (including $T_{2}, T_{3}$ ), with $c_{7}$ moving to the right. Furthermore, the feasible regions of Strategy $T$ and Strategy $T R$, both of which contain the trade-in program, remain unchanged when $s>s_{1}$. This is because the extra expenditure caused by the increase in the market recovery price can be partly compensated for by the profits generated from the sales of new products.

Proposition 7. (1) $\frac{\partial p_{r}^{i}}{\partial \theta}<0, \frac{\partial p_{r}^{T R_{1}}}{\partial \theta}=0$, and $\frac{\partial p_{t}^{j}}{\partial \theta}<0$, where $i=\left\{R_{1}, R_{2}, T R_{2}\right\}$ and $j=\left\{T_{1}, T_{2}, T_{3}, T R_{1}, T R_{2}\right\}$.

(2) $\frac{\partial p_{r}^{R_{1}}}{\partial \delta}>0\left(c<c_{1}+\delta\right), \frac{\partial p_{r}^{R_{1}}}{\partial \delta}<0\left(c>c_{1}+\delta\right), \frac{\partial p_{r}^{T R_{1}}}{\partial \delta}=0, \frac{\partial p_{r}^{i}}{\partial \delta}>0, \frac{\partial p_{t}^{T_{3}}}{\partial \delta}=0$, and $\frac{\partial p_{t}^{j}}{\partial \delta}>0$, where $i=\left\{R_{2}, T R_{2}\right\}$ and $j=\left\{T_{1}, T_{2}, T R_{1}, T R_{2}\right\}$.

Proposition 7 shows that the increased upgrade range of new products leads to a decrease in all optimal trade-in rebates because customers lower their requirements for trade-in rebates since they can get higher-quality new products, and the platform's profitability through trade-ins improves. The optimal recycling rebate of the single-recycling strategy and the recycling rebate of Strategy $T R_{2}$ also decrease monotonically with respect to $\theta$. The former is because the recycling rebate is actually tantamount to the trade-in rebate for the single-recycling rebate strategy, and the latter is because the recycling rebate decreases with the decrease in the trade-in rebate of Strategy $T R_{2}$. The recycling rebate of Strategy $T R_{1}$ is not related to $\theta$ because there are still some customers who keep using their old products under both rebates.

The impact of the durability of old products is relatively complicated. The increase in durability makes customers less willing to participate in recycling and trade-ins, so generally the platform should offer higher rebates. However, whether to increase or decrease the rebate of Strategy $R_{1}$ depends on the cost of new products, i.e., the profitability of trade-ins, because customers get the same amount of recycling rebate whether they choose recycling or trade-ins. The recycling rebate of Strategy $T R_{1}$ is not related to $\delta$, because the sum of the recycling rebate and the market recovery price is equivalent to the optimal recovery price without any constraints and the optimal rebate depends on the residual value of old products. However, the quantity of recycled old products $\frac{s}{2 \delta}$ drops with the increase in $\delta$. The trade-in rebate of Strategy $T_{3}$ is also not subject to $\delta$ for the same reason mentioned in the explanation for $\frac{\partial p_{t}^{T_{3}}}{\partial p_{c}}=0$ in Proposition 6, so we do not repeat it here.

To some extent, the change in the durability of old products reflects the change in the value of products during the whole life cycle. Generally speaking, the value of old products gets lower with the extension of time and the corresponding $\delta$ becomes lower. Therefore, we can conclude from Proposition 7 that B2C platforms should provide higher rebate prices so as to encourage those customers holding old products that are in the early life cycle to participate in recycling or trade-ins and that a higher recovery value of those old products makes the collaborative rebate strategy more applicable. However, customers have a stronger willingness to sell their old products that are in the late life cycle 
and the recovery value of those products is relatively low. Therefore the platforms just need to offer lower rebates or probably give up one of the two rebates. That is, the single rebate strategies become more applicable. In reality, considering the product life cycle, enterprises should make reasonable arrangements for the upgrading of products and pay attention to the collaboration of recycling and trade-ins in addition to the initial product design, so that they can strike a balance between meeting customers' needs and increasing their profits.

\section{Extended Discussion}

\subsection{When $p_{c} \geq \frac{\delta p}{1+\theta}$}

The results in Section 4 are based on $p_{c}<\frac{\delta p}{1+\theta}$. When $p_{c} \geq \frac{\delta p}{1+\theta}$, a relatively high market recovery price enables the platform to recycle all the old products without any additional rebates provided. Similar to Lemma 1, the platform could change the ratio of those customers who choose recycling to the other customers who choose trade-ins through the trade-in rebate without offering any rebate for recycling, that is, $p_{r}=0$. As far as customers are concerned, those customers with WTP in $\left[0, v_{t r}\right]$ choose recycling whereas the other customers with WTP in $\left[v_{t r}, 1\right]$ choose trade-ins, where $v_{t r}=\frac{p-p_{t}}{1+\theta}$. The platform just needs to decide the optimal trade-in rebate to maximize its profits.

$$
\begin{gathered}
\pi=\left(p-c+s-p_{c}-p_{t}\right)\left(1-v_{t r}\right)+\left(s-p_{c}\right) v_{t r} \\
\text { s.t. } p_{t} \geq 0
\end{gathered}
$$

Constraint (9) shows that there are only two rebate strategies applicable now. The platform offers trade-in rebates when $p_{t}>0$, but does not provide any rebates when the equal sign is taken.

Proposition 8. When $c \leq c_{8}, p_{t}=\frac{2 p-c-(1+\theta)}{2}$, i.e., Strategy $T_{3}$ applies and cannibalization complete recycling is achieved. When $\mathrm{c}>c_{8}$, no additional rebates are necessary, i.e., Strategy $B$ applies, where $c_{8}=2 p-(1+\theta)$. The platform's decisions are shown in Figure 3.

Proposition 8 shows that when the market recovery price is high enough, the platform is able to recycle all the old products despite no additional rebates offered and that the WTP of critical customers between choosing to recycle alone and choosing to buy new products after recycling is not subject to the market recovery price $\left(v_{t r}=\frac{p-p_{t}}{1+\theta}\right)$. The set of the platform's strategies is narrowed down to the decision of whether or not to provide the trade-in rebate. When the cost of new products is relatively low, the unit profit from selling new products becomes relatively high and it is more beneficial for the platform to include those customers whose original choice is just recycling old products by offering the trade-in rebate. When the cost of new products is relatively high, then it is wiser to give up the trade-in rebate.

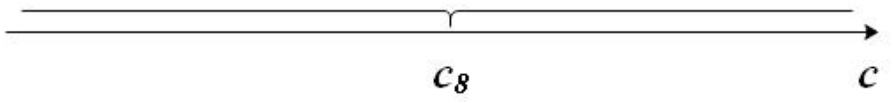

Figure 3. The platform's optimal rebate strategy when $p_{c} \geq \frac{\delta p}{1+\theta}$.

\subsection{When $p_{c}=0$}

When $p_{c}=0$, the B2C platform no longer needs to decide on additional rebates for recycling and trade-ins based on the market recovery price. Instead, the platform decides whether to implement the recycling program and the trade-in program. At this time, Strategy $R$ and Strategy $T$ refer to the implementation of the recycling program and the trade-in program separately. Strategy TR stands for simultaneous implementation of both 
programs, and Strategy $B$ is abandoning both programs. Substituting $p_{c}=0$ into the above results, we arrive at the platform's decisions as shown in Figure 4.

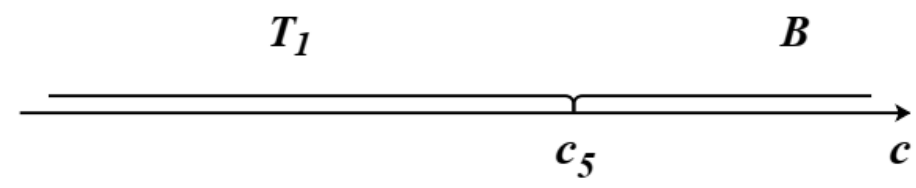

(a) when $s<s_{1}$

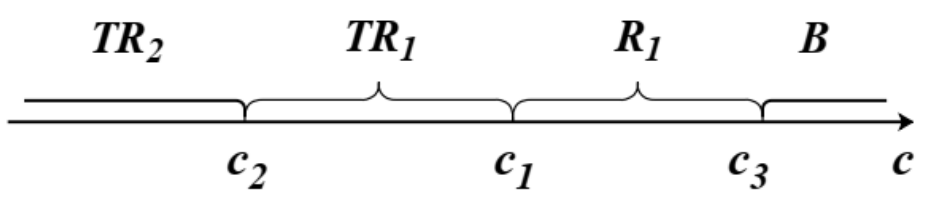

(b) when $s_{1} \leq s \leq s_{2}$

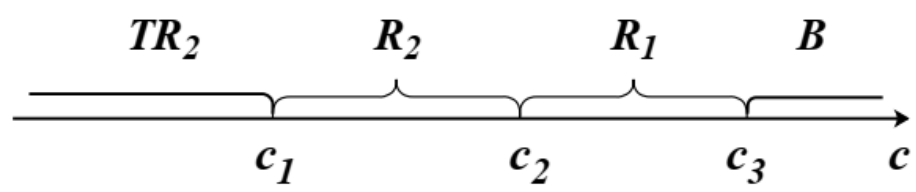

(c) when $s>s_{2}$.

Figure 4. The collaborative strategy for recycling and trade-ins when $p_{c}=0$.

From Figure 4, we know that when capable of implementing both the recycling program and the trade-in program, the platform considers the trade-in program alone only when the residual value of old products is negative $\left(s<s_{1}=0\right)$ and the positive profits from selling new products allow the platform to bear the loss from recycling old products in the trade-in process. Otherwise, the platform should implement the recycling program unless the cost of new products is too high. If the residual value of old products is non-negative and the cost of new products is relatively low, implementing both programs simultaneously is the optimal strategy. The platform can theoretically abandon both programs, but choosing either one alone or two at the same time is a dominant strategy in most cases because the critical costs $\left.c_{3}\right|_{p_{c}=0}=2 p+\frac{1+\theta}{\delta} s-(1+\theta-\delta)$ and $\left.c_{5}\right|_{p_{c}=0}=2 p+s-(1+\theta-\delta)$ are very large, which corresponds with the raging practice of both programs on JD.com and Suning.com. Our finding is also similar to the conclusions Xiao and Zhou [1] drew through numerical experiments. The difference lies in that their paper considered that the implementation of both programs simultaneously is always a dominant strategy whereas our paper gives the feasible conditions for the four strategies through model deduction.

The question now is whether the platform should choose to cooperate with professional recycling companies instead of implementing the recycling program and the trade-in program independently. We found from Proposition 6 that the market recover price $p_{c}$ has no negative effects on the profits of different strategies. Does that mean that the strategic cooperation between the platform and recycling companies is of no importance? In fact, in our model we do not consider the comparative advantages of professional recycling companies compared to the platform in the cost incurred during the recycling process. Professional recycling companies have more specialized equipment and experienced staff with lower costs of evaluating and testing old products as well as logistics costs. Under such a partnership, the platform loses part of its pricing power, which may lead to partial loss of profits. However, the platform could save a lot of operating costs, and increase its profits as much as possible through collaboration of the recycling rebate and the trade-in rebate. Overall, the advantages of cooperation outweigh the disadvantages. that is why JD.com and Suning.com choose to cooperate with professional recycling companies. 


\subsection{The Influences of Cross-Selling}

In the above discussion, the platform pays customers in cash for the market recovery price and the recycling rebate during the recycling program, and customers just pay the price spread between the price of new products and the sum of the market recovery price and the trade-in rebate during the trade-in program. In practice, the process of recycling and trade-ins is varied on B2C platforms. For example, another common process of tradeins is like this: Customers make full payments first for new products after old products are tested online and given a recovery price, and receive the rebate after the recycling of old products is completed. That is the case with the trade-in program on JD.com for the new Huawei P40. What is more, the money of the market recovery price for recycled old products and additional rebates are released to customers' accounts on the platform in the trade-in program, which is the same as the payment method in the recycling program. Customers can either withdraw this sum of money to their own bank cards or use the money for purchasing something again on the platform, which is the cross-selling for the platform if they make the second choice. The platform often pays customers the money of the market recovery price in cash and offers them additional rebates in the form of gift cards that can only be used on the platform such as JD E-cards or Suning cards to encourage customers' further consumption. This indicates that the platform is able to make more money through cross-selling in the process of recycling and trade-ins, which makes the value of old products greater than the actual residual value.

The existence of cross-selling indeed stands for the increase in the residual value of old products for the platform, so we assume that the value of old products is $k s$, and $k>1$. The parameter $k$ stands for the platform's profitability from cross-selling, which, to some extent, represents the stickiness of the platform or customers' continuous willingness to purchase on the platform. By substituting $k s$ for $s$ in the aforementioned results, we can get optimal rebates and feasible conditions for different strategies considering the influence of cross-selling. Obviously, $\frac{\partial p_{r}^{R_{1}}}{\partial k}>0, \frac{\partial p_{t}^{T_{1}}}{\partial k}>0, \frac{\partial p_{r}^{T R_{1}}}{\partial k}>0, \frac{\partial p_{t}^{T R_{1}}}{\partial k}>0$, and $\frac{\partial p_{r}^{R_{2}}}{\partial k}=\frac{\partial p_{t}^{T_{2}}}{\partial k}=$ $\frac{\partial p_{t}^{T_{3}}}{\partial k}=\frac{\partial p_{r}^{T R_{2}}}{\partial k}=\frac{\partial p_{t}^{T R_{2}}}{\partial k}=0$. That is, when it comes to partial recycling, the existence of cross-selling facilitates the platform's willingness to offer higher rebates, including the recycling rebate and the trade-in rebate, which helps to improve the number of recycled old products and obtain greater profits. When it comes to complete recycling, cross-selling has no effects on those rebates, and the platform's profits rise due to the increase in the unit old product value.

Moreover, when the residual value of old products is relatively low, the existence of cross-selling makes it possible that the value of old products exceeds the critical point of the residual value $s_{1}$, causing the collaboration of the recycling rebate and the trade-in rebate to be more important. From $\frac{\partial c_{2}}{\partial k}>0, \frac{\partial c_{3}}{\partial k}>0, \frac{\partial c_{4}}{\partial k}>0$, and $\frac{\partial c_{5}}{\partial k}>0$, we know that the respective boundary of the feasible intervals of the new product cost for Strategies $R_{1}, T_{1}$, and $T R_{1}$ moves to the right, the feasible space of the non-rebate strategy is compressed, and the feasible interval of Strategy $T R_{2}$ is expanded. As a consequence, the platform tends to raise rebates so as to recycle more old products.

In one word, the profits from cross-selling promote the B2C platform's implementation of the collaborative rebate strategy. On the one hand, the operation of the recycling program and the trade-in program provides customers with an opportunity for continuous consumption and improves the consumption stickiness. On the other hand, the platform tries its best to offer customers richer categories and better-quality service aside from mandatory gift cards so that more customers are willing to use their rebates for another purchase on the platform, which certainly will enjoy an increase in profits from both programs.

\section{Conclusions}

The popularity of smartphones and the development of e-commerce facilitate the rapid growth of platform-oriented enterprises, and customers are getting more used to buying new products and having old products recycled on the platforms. Besides, 
huge investments, professional requirements, and the complicated process of recycling old products enable the platforms to be open to cooperation with professional recycling companies. Under such a realistic background, we studied the optimal collaborative rebate strategy based on the exogenous market recovery price and gave the optimal rebates and feasible conditions for the single-recycling rebate strategy, single-trade-in rebate strategy, dual-rebate strategy, and non-rebate strategy.

The results show that when the residual value of old products is relatively low, or when the residual value of old products is relatively high but the cost of new products is relatively low, the single-trade-in strategy is dominant; when the residual value of old products is relatively high and the cost of new products is moderate, the dual-rebate strategy is dominant; when both the residual value of old products and the cost of new products are relatively high, the single-recycling rebate strategy is dominant; when the cost of new products is extremely high, the non-rebate strategy is dominant. Furthermore, with the increase in the residual value of old products and the decrease in the cost of new products, the total quantity of old products recycled rises. As a result, partial recycling is in transition to exactly complete recycling and even to cannibalization complete recycling.

Now we remark on the contribution of this paper. Theoretically, we considered the operational characteristics of the recycling and trade-in programs on B2C platforms, including the rebates based on the exogenous market recycling price of old products and cross-selling as well, and built a decision-making model for maximizing the platforms' profits under the collaboration of the two programs. Through strict theoretical derivation, we finally obtained the optimal prices and feasible conditions of the four possible rebate strategies. However, the existing literature rarely includes recycling and trade-ins at the same time. Although Xiao and Zhou [1] considered both programs, they did not make a strict theoretical comparison about the differences between implementing one single program and two programs or about their applicable situations. According to their study, the pricing decision is limited to the default situation where two programs are implemented simultaneously. What is more, they drew a single conclusion through numerical experiments that enterprises should always implement two programs simultaneously. The model and conclusions of our paper are to enrich the current research results. Furthermore, the conclusion of our paper provides practical reference for B2C platforms that consider recycling and trade-ins simultaneously. The platforms should take into full consideration the market recovery price, the residual value and the durability of old products, and the cost, price, and upgrade range of new products, along with the cross-selling phenomenon. Proper rebates should be offered by the platforms to better coordinate the recycling program and the trade-in program, which help to generate greater profits.

Based on our paper, further study can be conducted from the following aspects. We only considered the consumer group that holds old products and excluded newly arrived customers, so we did not discuss the pricing decision of new products. The price of new products is a decision variable for B2C platforms owned by some large manufacturers such as Huawei, Xiaomi, and Gree. At this time, the collaborative rebate strategy for recycling and trade-ins might change. In addition, we focused on the optimization of the rebate strategies of B2C platforms with an aim of maximizing the platforms' profits, but did not consider the environmental benefits of those strategies. That is worth conducting further study on in the future because environmental benefits might limit the platforms choices of strategies. Another significant direction to consider is the competition between different platforms.

Author Contributions: Conceptualization, G.J., Z.S. and K.H.T.; methodology, Z.S.; software, Z.S.; writing — original draft preparation, Z.S.; writing—review and editing, G.J. and K.H.T.; funding acquisition, G.J. All authors have read and agreed to the published version of the manuscript.

Funding: This research was funded by the National Natural Science Foundation of China, grant numbers 71871197, 71872158, and 71571151.

Institutional Review Board Statement: Not applicable. 
Informed Consent Statement: Not applicable.

Data Availability Statement: Not applicable.

Conflicts of Interest: The authors declare no conflict of interest.

\section{Appendix A}

Proof of Lemma 1. When $p_{c}<\frac{\delta p}{1+\theta}$ and $v_{r}>v_{t}$, customers choose either trade-ins or recycling. Under the equilibrium state, it is obviously uneconomical for the platform to offer higher recycling rebates and trade-in rebates to break the critical customer's equilibrium if their WTP is larger than $\frac{p_{c}}{\delta}$. It is cost-optimal to make $v_{r}=v_{t}$ under rebate strategies, which is contradictory to $v_{r}>v_{t}$. Therefore, the WTP of the critical customer is not higher than $\frac{p_{c}}{\delta}$ when $v_{r}>v_{t}$, where $\frac{p_{c}}{\delta}$ is the strongest WTP of those customers who still choose the recycling program at the market recovery price. Under the situation $v_{r}>v_{t}$, the WTP of the customers who choose the recycling program is weaker than $\frac{p_{c}}{\delta}$, so it is unnecessary for the platform to offer additional recycling rebates, i.e., $p_{r}=0$.

Proof of Propositions 1 to 4. When $p_{c}<\frac{\delta p}{1+\theta}$, we should solve the problem of Equation (1) if $v_{r} \leq v_{t}$.

The Hessian matrix is $H_{1}=\left[\begin{array}{cc}\frac{-2}{1+\theta-\delta} & 0 \\ 0 & \frac{-2}{\delta}\end{array}\right]$. The determinant is $\left|H_{1}\right|>0$ and $\frac{-2}{1+\theta-\delta}<0$, so the platform's optimization problem is a concave programming problem. The Lagrangian function is defined as $L=\pi+\lambda_{1} p_{r}+\lambda_{2}\left(p_{t}-p_{r}\right)+\lambda_{3}\left(\frac{p-p_{c}-p_{t}}{1+\theta-\delta}-\frac{p_{c}+p_{r}}{\delta}\right)$.

(1) When $\lambda_{2} \neq 0$ and $\lambda_{1}=\lambda_{3}=0$, the KKT conditions are solved and the optimal solution is obtained: $p_{r}^{R_{1}}=\frac{s}{2}+\frac{\delta(2 p-c-1-\theta+\delta)}{2(1+\theta)}-p_{c}$. We named it Strategy $R_{1}$ of the singlerecycling rebate strategy, and partial recycling is achieved. From $p_{r} \geq 0$ we get $c \leq c_{3}$, from $v_{r} \leq v_{t}$ we get $c \geq c_{2}$, and from $\lambda_{2}=\frac{1+c-\delta-2 p+\theta}{1+\theta}>0$ we get $c>c_{1}$. When $c_{3}-c_{1}=\frac{1+\theta}{\delta} s-\frac{2(1+\theta)}{\delta} p_{c} \geq 0, s \geq s_{1}$; when $c_{2}-c_{1}=\frac{1+\theta}{\delta} s-2 p \geq 0, s \geq s_{2}$. Therefore, the feasible conditions for Strategy $R_{1}$ are $s_{1} \leq s \leq s_{2}, c_{1}<c \leq c_{3}, s>s_{2}$, and $c_{2} \leq c \leq c_{3}$.

$c^{2} \delta^{2}+\delta^{4}+2 \delta^{3}(-1+2 p-\theta)+s^{2}(1+\theta)^{2}+2 \delta(1+\theta)\left(-2 p^{2}+(2 p+s)(1+\theta)\right)+\delta^{2}\left(4 p^{2}-8 p(1+\theta)-(-1+2 s-\theta)(1+\theta)\right)$ $-2 c \delta\left(\delta^{2}+2 \delta p-3 \delta(1+\theta)+(1+\theta)(2-2 p+s+2 \theta)\right)$

(2) When $\lambda_{2} \neq 0, \lambda_{3} \neq 0$, and $\lambda_{1}=0$, the optimal solution is $p_{r}^{R_{2}}=\frac{\delta p}{1+\theta}-p_{c}$. We named it Strategy $R_{2}$ of the single-recycling rebate strategy and exactly complete recycling is achieved. From $\lambda_{3}=\frac{\delta^{2}+s(1+\theta)-\delta(1+c+\theta)}{\delta(1+\theta)}>0$ we get $c<c_{2}$ and from $\lambda_{2}=\frac{1+\theta-\delta-2 p+c}{1+\theta}>0$ we get $c>c_{1}$. Therefore, the feasible conditions for Strategy $R_{2}$ are $s>s_{2}$ and $c_{1}<c<c_{2}$.

$$
\pi_{R 2}=\frac{(1+\theta)(p+s-c)-p(p+\delta-c)}{1+\theta}
$$

(3) When $\lambda_{1} \neq 0$ and $\lambda_{2}=\lambda_{3}=0$, the optimal solutions are $p_{r}^{T_{1}}=0$ and $p_{t}^{T_{1}}=$ $\frac{2\left(p-p_{c}\right)+s-c-(1+\theta-\delta)}{2}$. We named it Strategy of the single-trade-in rebate strategy and partial recycling is achieved. From $p_{t} \geq 0$ we get $c \leq c_{5}$, from $v_{r} \leq v_{t}$ we get $c \geq c_{4}$, and from $\lambda_{1}=-\frac{s-2 p_{c}}{\delta}>0$ we get $s<s_{1}$. In addition, $c_{5}-c_{4}=2 \mathrm{p}-2 p_{c} \frac{1+\theta}{\delta}>0$ is always true. Therefore, Strategy $T_{1}$ is feasible when $s<s_{1}$ and $c_{4} \leq c \leq c_{5}$.

$$
\pi_{T 1}=\frac{(1+\theta-\delta+s-c)^{2}}{4(1+\theta-\delta)}+\frac{p_{c}\left(s-p_{c}\right)}{\delta}
$$


(4) When $\lambda_{1} \neq 0, \lambda_{3} \neq 0$, and $\lambda_{2}=0$, the optimal solutions are $\mathrm{t} p_{r}^{T_{2}}=0$ and $p_{t}^{T_{2}}=\frac{\delta p-(1+\theta) p_{c}}{\delta}$. We named it Strategy $T_{2}$ of the single-trade-in rebate strategy and exactly complete recycling is achieved. From $\lambda_{3}=\frac{\delta^{2}+2 p_{c}(1+\theta)-\delta\left(1+c+2 p_{c}-s+\theta\right)}{\delta^{2}}>0$ we get $c<c_{4}$, from $\lambda_{1}=\frac{\delta^{2}+2 p_{c}(1+\theta)-\delta(1+c+\theta)}{\delta^{2}}>0$ we get $c<c_{7}$, and when $c_{4}-c_{7}=s-2 p_{c} \geq 0, s \geq s_{1}$. Therefore, the feasible conditions for Strategy $T_{2}$ are $s<s_{1}, c<c_{4}, s \geq s_{1}$, and $c<c_{7}$.

$$
\pi_{T 2}=\frac{c \delta\left(-\delta+p_{c}\right)+\delta^{2}\left(-p_{c}+s\right)+\delta p_{c}(1+\theta)-p_{c}^{2}(1+\theta)}{\delta^{2}}
$$

(5) When $\lambda_{1}=\lambda_{2}=\lambda_{3}=0$, the optimal solutions are $p_{r}^{T R_{1}}=\frac{s-2 p_{c}}{2}$ and $p_{t}^{T R_{1}}=$ $\frac{2\left(p-p_{c}\right)+s-c-(1+\theta-\delta)}{2}$. We named it Strategy $T R_{1}$ of the dual-rebate strategy and partial recycling is achieved. From $p_{r} \geq 0$ we get $s \geq s_{1}$, from $p_{t} \geq p_{r}$ we get $c \leq c_{1}$, and from $v_{r} \leq v_{t}$ we get $c \geq c_{2}$. When $c_{2}-c_{1}=\frac{1+\theta}{\delta} s-2 p \geq 0, s \geq s_{2}$. Therefore, the feasible conditions for Strategy $T R_{1}$ are $s_{1} \leq s \leq s_{2}$ and $c_{2} \leq c \leq c_{1}$.

$$
\pi_{T R 1}=\frac{(1+\theta-\delta+s-c)^{2}}{4(1+\theta-\delta)}+\frac{s^{2}}{4 \delta}
$$

(6) When $\lambda_{3} \neq 0$ and $\lambda_{1}=\lambda_{2}=0$, the optimal solutions are $p_{r}^{T R_{2}}=\frac{(1+\theta-\delta)+c}{2(1+\theta)} \delta-p_{c}$ and $p_{t}^{T R_{2}}=\frac{2(1+\theta)\left(p-p_{c}\right)-(1+\theta-\delta) c-(1+\theta-\delta)^{2}}{2(1+\theta)}$. We named it Strategy $T R_{2}$ of the dual-rebate strategy and exactly complete recycling is achieved. From $p_{r} \geq 0$ we get $c \geq c_{7}$, from $p_{t} \geq p_{r}$ we get $c \leq c_{1}$, and from $\lambda_{3}=\frac{\delta^{2}+s(1+\theta)-\delta(1+c+\theta)}{\delta(1+\theta)}>0$ we get $c<c_{2}$. When $c_{2}-c_{1}=\frac{1+\theta}{\delta} s-2 p \geq 0, s \geq s_{2} ; c_{1}-c_{7}=2 p-\frac{2(1+\theta)}{\delta} p_{c}>0$ is always true; when $c_{2}-c_{7}=\frac{1+\theta}{\delta} s-\frac{2(1+\theta)}{\delta} p_{c} \geq 0, s \geq s_{1}$. Therefore the feasible conditions for Strategy $T R_{2}$ are $s_{1} \leq s \leq s_{2}, c_{7} \leq c<c_{2}, s>s_{2}$, and $c_{7} \leq c \leq c_{1}$.

$$
\pi_{T R 2}=\frac{c^{2}+\delta^{2}-2 \delta(1+\theta)-2 c(1+\delta+\theta)+(1+\theta)(1+4 s+\theta)}{4(1+\theta)}
$$

(7) When $\lambda_{1} \neq 0, \lambda_{2} \neq 0$, and $\lambda_{3} \neq 0$, there is no solution.

(8) When $\lambda_{1} \neq 0, \lambda_{2} \neq 0$, and $\lambda_{3}=0, p_{r}^{B}=0$ and $p_{t}^{B}=0$, obviously. We named it Strategy $B$ or the non-rebate strategy, and partial recycling is achieved. From $\lambda_{2}=$ $\frac{1+c-\delta-2 p+2 p_{c}-s+\theta}{1+\theta-\delta}>0$ we get $c>c_{5}$ and from $\lambda_{1}=\frac{-\delta^{2}+\left(2 p_{c}-s\right)(1+\theta)+\delta(1+c-2 p+\theta)}{\delta(1+\theta-\delta)}>0$ we get $c>c_{3}$; when $c_{3}-c_{5}=\frac{1+\theta-\delta}{\delta} s-\frac{1+\theta-\delta}{\delta} 2 p_{c} \geq 0, s \geq s_{1}$. Therefore, the feasible conditions for Strategy $B$ are $s \geq s_{1}$ and $c>c_{3}$, and $s<s_{1}$ and $c>c_{5}$.

$$
\pi_{B}=\left(p-p_{c}+s-c\right)\left(1-\frac{p-p_{c}}{1+\theta-\delta}\right)+\left(s-p_{c}\right) \frac{p_{c}}{\delta}
$$

When $p_{c}<\frac{\delta p}{1+\theta}$, we should solve the problem of Equation (5) if $v_{r}>v_{t}$.

Obviously, the profit function is concave. We defined the Lagrangian function as $L=\pi+\lambda\left(\frac{p-p_{c}-p_{t}}{1+\theta-\delta}-\frac{p_{c}}{\delta}\right)$.

(1) When $\lambda=0$ we get the optimal solutions: $p_{r}^{T_{3}}=0$, and $p_{t}^{T_{2}}=\frac{\delta p-(1+\theta) p_{c}}{\delta}$. We called it Strategy $T_{3}$ of the single-trade-in rebate strategy, and cannibalization complete recycling is achieved. From $v_{r} \geq v_{t}$ we get $\mathrm{c} \leq c_{6}$, which is the feasible condition for Strategy $T_{3}$.

$$
\pi_{\mathrm{T} 3}=\frac{1}{4}\left(1-2 c-4 p_{c}+4 s+\theta+\frac{c^{2}}{1+\theta}\right)
$$

(2) When $\lambda \neq 0$ we get the optimal solutions: $p_{r}^{T_{2}}=0$ and $p_{t}^{T_{2}}=\frac{\delta p-(1+\theta) p_{c}}{\delta}$. Obviously, it is Strategy $T_{2}$ of the single-trade-in rebate strategy. From $\lambda=\frac{(1-d+\theta)\left(-2 p_{c}(1+\theta)+\delta(1+c+\theta)\right)}{\delta(1+\theta)}>0$ 
we get $\mathrm{c}>c_{6}$. By combining the above result (4) when $v_{r} \leq v_{t}$, both $c_{4}-c_{6}=\mathrm{s}+\delta-2 p_{c}>0$ and $c_{7}-c_{6}=\delta>0$ are true. Therefore, the whole feasible conditions for Strategy $T_{2}$ are $s<s_{1}$ and $c_{6}<c<c_{4}$, and $s \geq s_{1}$ and $c_{6}<c<c_{7}$.

Proof of Proposition 5. It can be proved easily with a combination of the respective feasible conditions for the strategies in Propositions 1 to 4 .

Proof of Proposition 6 and 7. We can calculate the derivatives of the optimal solutions above with respect to $p_{c}, \theta$, and $\delta$. The calculation is simple so we omitted it.

Proof of Proposition 8. When $p_{c} \geq \frac{\delta p}{1+\theta}$, we should solve the problem of Equation (8). Obviously, the profit function is concave. The Lagrangian function is $L=\pi+\lambda p_{t}$.

(1) When $\lambda=0$, the optimal solution is $p_{t}^{T_{3}}=\frac{2 p-c-(1+\theta)}{2}$. We get Strategy $T_{3}$ of the single-trade-in rebate strategy. From $p_{t} \geq 0$, we get the feasible condition for this strategy: $c \leq c_{8}$.

$$
\pi_{\mathrm{T} 3}=\frac{1}{4}\left(1-2 c-4 p_{c}+4 s+\theta+\frac{c^{2}}{1+\theta}\right)
$$

(2) When $\lambda_{1} \neq 0$ and $p_{t}^{B}=0$, the non-rebate strategy is optimal. From $\lambda_{1}=\frac{1+c-2 p+\theta}{1+\theta}>0$. we get $c>c_{8}$.

$$
\pi_{B}=(p-c)\left(1-\frac{p}{1+\theta}\right)+s-p_{c}
$$

\section{References}

1. Xiao, Y.; Zhou, S.X. Trade-in for cash or for upgrade? Dynamic pricing with customer choice. Prod. Oper. Manag. 2020, 29, 856-881. [CrossRef]

2. Savaskan, R.C.; Bhattacharya, S.; Van Wassenhove, L.N. Closed-loop supply chain models with product remanufacturing. Manag. Sci. 2004, 50, 239-252. [CrossRef]

3. Savaskan, R.C.; Van Wassenhove, L.N. Reverse channel design: The case of competing retailers. Manag. Sci. 2006, 52, 1-14. [CrossRef]

4. Atasu, A.; Toktay, L.B.; Van Wassenhove, L.N. How collection cost structure drives a manufacturer's reverse channel choice. Prod. Oper. Manag. 2013, 22, 1089-1102. [CrossRef]

5. Vorasyan, J.; Ryan, S.M. Optimal price and quantity of refurbished products. Prod. Oper. Manag. 2006, 15, 369-383. [CrossRef]

6. Atasu, A.; Cetinkaya, S. Lot sizing for optimal collection and use of remanufacturable returns over a finite life-cycle. Prod. Oper. Manag. 2006, 15, 473-487. [CrossRef]

7. Hammond, D.; Beullends, P. Closed-loop supply chain network equilibrium under legislation. Eur. J. Oper. Res. 2007, 183, 895-908. [CrossRef]

8. Toyasaki, F.; Boyact, T.; Verter, V. An analysis of monopolistic and competitive takeback schemes for WEEE recycling. Prod. Oper. Manag. 2011, 20, 805-823. [CrossRef]

9. Jacobs, B.W.; Subramanian, R. Sharing responsibility for product recovery across the supply chain. Prod. Oper. Manag. 2012, 21, 85-100. [CrossRef]

10. Miao, Z.; Fu, K.; Xia, Z.; Wang, Y. Models for closed-loop supply chain with trade-ins. Omega 2017, 66, 308-326. [CrossRef]

11. Huang, Y. A closed-loop supply chain with trade-in strategy under retail competition. Math. Probl. Eng. 2018, 1-16. [CrossRef]

12. Ray, S.; Boyaci, T.; Aras, N. Optimal prices and trade-in rebates for durable, remanufacturable products. Manuf. Serv. Oper. Manag. 2005, 7, 208-228. [CrossRef]

13. Ma, Z.J.; Zhou, Q.; Dai, Y.; Guan, G.F. To license or not to license remanufacturing business? Sustainability 2018, 10, 347. [CrossRef]

14. Cao, K.; Wang, J.; Dou, G.; Zhang, Q. Optimal trade-in strategy of retailers with online and offline sales channels. Comput. Ind. Eng. 2018, 123, 148-156. [CrossRef]

15. Feng, L.; Li, Y.; Fan, C. Optimization of pricing and quality choice with the coexistence of secondary market and trade-in program. Ann. Oper. Res. 2020. [CrossRef]

16. Liu, J.; Zhai, X.; Chen, L. The interaction between product rollover strategy and pricing scheme. Int. J. Prod. Econ. 2018, 201, 116-135. [CrossRef]

17. Yin, R.; Li, H.; Tang, C.S. Optimal pricing of two successive-generation products with trade-in options under uncertainty. Decis. Sci. 2015, 46, 565-595. [CrossRef] 
18. Liu, J.; Zhai, X.; Chen, L. Optimal pricing strategy under trade-in program in the presence of strategic consumers. Omega 2019, 84, 1-17. [CrossRef]

19. Hu, S.; Ma, Z.; Sheu, J. Optimal prices and trade-in rebates for successive-generation products with strategic consumers and limited trade-in duration. Transp. Res. Part. E-Log. 2019, 124, 92-107. [CrossRef]

20. Rao, R.S.; Narasimhan, O.; John, G. Understanding the role of trade-ins in durable goods markets: Theory and evidence. Mark. Sci. 2009, 28, 950-967. [CrossRef]

21. Desai, P.S.; Purohit, D.; Zhou, B. The strategic role of exchange promotions. Mark. Sci. 2016, 35, $93-112$.

22. Wang, C.; Zhu, T.; Yao, H.; Sun, Q. The impact of green information on the participation intention of consumers in online recycling: An experimental study. Sustainability 2020, 12, 2498. [CrossRef]

23. Miao, S.; Liu, D.; Ma, J. O2O recycling closed-loop supply chain modeling based on classification process considering environmental index. Discret. Dyn. Nat. Soc. 2020, 2020, 1-15. [CrossRef]

24. Cao, K.; Xu, X.; Bian, Y.; Sun, Y. Optimal trade-in strategy of business-to-consumer platform with dual-format retailing model. Omega 2019, 82, 181-192. [CrossRef]

25. Cao, K.; Han, G.; Xu, B.; Wang, J. Gift card payment or cash payment: Which payment is suitable for trade-in rebate? Transp. Res. Part. E-Log. 2020, 134, 101857. [CrossRef] 